\title{
Glucose and Insulin Metabolism in Twins: Influence of Zygosity and Birth Weight
}

\author{
Pernille Poulsen and Allan Vaag \\ Diabetes Research Center, Odense University Hospital, Odense, Denmark and Steno Diabetes Center, Gentofte, Denmark
}

\begin{abstract}
Several epidemiological and metabolic studies have demonSstrated an impact of the intrauterine environment on the development of disease in adult life, including Type 2 diabetes and glucose intolerance. Our finding of lower birth weights among monozygotic diabetic twins compared to their non-diabetic genetically identical co-twins confirms this association and, furthermore, eliminates the possibility that the association could be explained solely by common genes leading to both impaired intrauterine growth and increased risk of Type 2 diabetes. Due to an often shared placenta monozygotic twins may experience a more adverse intrauterine environment compared to dizygotic twins and may therefore be more prone to develop various metabolic abnormalities. Our findings of a higher glucose and insulin profile after oral glucose ingestion, and recently lower insulin-stimulated glucose uptake - indicating glucose intolerance and insulin resistance - among monozygotic compared to dizygotic twins may to some extent question the validity of classical twin studies in diabetes research where equal environmental influences in monozygotic and dizygotic twins is assumed. The potential role of an adverse intrauterine environment in causing Type 2 diabetes in humans, may to some degree alter our conception of the twin model in diabetes research including the interpretation of aetiological conclusions reached in previous classical twin studies of diabetes. However, our present knowledge is far too insufficient to discard the results from classical twin studies concerning the relative role of genes versus environment for the development of diabetes and its metabolic effects.
\end{abstract}

In the past decade several epidemiological and metabolic studies have demonstrated an impact of the intrauterine environment (i.e. low birth weight) for the development of disease in adult life, including primarily states of diseases related to the metabolic syndrome (i.e. diabetes, glucose intolerance, obesity, hypertension and dyslipidaemia). Twins experience a more adverse intrauterine environment and consequently lower birth weights compared to singletons.

Nevertheless, twin studies have been used extensively in medical research to determine the relative influence of genetic versus environmental factors in the aetiology of human disease. The classical twin design takes advantage of the fact that monozygotic (MZ) twins share the same genes, whereas dizygotic (DZ) twins, like siblings, only share approximately $50 \%$ of the same genes. A prerequisite for the validity of aetiological conclusions drawn from the classical twin model is that MZ and DZ twins are influenced to the same extent by both pre- and postnatal environmental factors, and in that sense in particular by factors with potential influence on the phenotype or disease in question.
The new knowledge concerning the potential role of an adverse intrauterine environment in causing Type 2 diabetes, hypertension and cardiovascular disease in man, may to some degree alter our conception of the twin model in diabetes research including the interpretation of aetiological conclusions reached in previous diabetes twin studies. A consequence of this is that we have reached a new understanding of how twins can be used as a tool to improve our knowledge about intrauterine operating disease mechanisms. The aim of this review was to apply an updated view of our findings on the association between intrauterine environment and glucose and insulin metabolism using different twin approaches and furthermore to discuss the impact of these findings on the classical twin model.

\section{Twin Embryology}

Around one-third of twins are MZ and develop from one single fertilised ovum. The splitting of the zygote can occur at different stages of development. The earliest separation is at the two-cell stage, leading to the development of two separate zygotes. This occurs in approximately one-third of MZ twins. These twins have their own placenta and chorion membranes and are referred to as MZ, dichorionic twins. Approximately two-thirds of monozygtic twins are monochorionic due to a later splitting at the blastocyst stage. The twins have a common placenta and chorion cavity but have separate amnion cavities. Rarely, the splitting occurs even later at the bilaminar germ disc stage resulting in twins sharing the same placenta, chorion and amnion cavities, i.e. monochorionic, monoamnionic twins. The remaining twothirds of twins are DZ. They develop due to fertilisation of two oocytes, and consequently they have a different genetic constitution. Although each embryo normally has its own amnion, chorion and placenta, the placentas may sometimes be fused. However, each embryo usually receives the appropriate amount of blood and nutritives (Sadler, 1995).

Twin pregnancies per se have a higher risk of intrauterine malnutrition, low birth weight and perinatal morbidity and mortality compared to singleton pregnancies (Bjōro \& Bjōro, 1985, Naeye et al., 1966; Ramas-Arroyo et al., 1988).

Address for correspondence: Dr. Pernille Poulsen, Diabetes Research Center, Dept. of Endocrinology, Odense University Hospital, Sdr. Boulevard 29, DK-5000 Odense C, Denmark. Email: p.poulsen@winsloew.ou.dk. 
In addition, the sharing of the same nutritive source and the development of vascular anastamoses among $\mathrm{MZ}$ twins result in a different and more adverse intrauterine environment (i.e. lower birth weight) than among DZ twins who have separate placentas. Dichorionic MZ and DZ twins are heavier than monochorionic MZ twins, indicating that chorionic membranes may be a more important determinant of birth weight than zygosity. In addition, DZ twins with a fused placenta have a tendency to lower birth weights than DZ twins with separate placentas (Bjōro \& Bjơro, 1985; Ramas-Arroyo et al., 1988).

Whether intrapair birth weight difference among $\mathrm{MZ}$ twins - due to the shared placenta - is greater compared to the intrapair difference among DZ twins is unclear (Bjoro \& Bjóro, 1985; Naeye et al., 1966; Ramas-Arroyo et al., 1988). The placental vascular anastomoses in monochorionic placentas are usually arranged in a balanced manner. However, in 5-15\% of monochorionic twin pregnancies the vascularisation is unequally distributed among the two twins resulting in the twin-transfusion syndrome. In this case one twin receives most of the blood flow while the other is compromised, leading to a large intrapair birth weight difference among the pair. This particular phenomenon results in the death of both twins in $60-100 \%$ of cases, and may consequently only explain a negligible part of the intrapair birth weight difference in living twin samples (Sadler, 1995).

\section{The Fetal Origins Hypothesis}

The fetal origins hypothesis is based on the consistent findings of associations between low birth weight and abnormal glucose tolerance, hypertension and coronary heart disease (Hales et al., 1991; Hales \& Barker, 1992). Subsequently, the associations between abnormal glucose tolerance and low birth weight were later confirmed in a variety of different populations including Danish twins (Poulsen et al., 1997). The original hypothesis included the proposal of a defective beta cell function associated with poor early nutrition that only would become detrimental in subjects who later in an advanced age were exposed to a sedentary life style and obesity. Meanwhile, subsequent studies have indicated that low birth weight in man is associated with insulin resistance (Hofman et al., 1997; Phillips et al., 1994) and/or hyperinsulinaemia (Leger et al., 1997; Valdez et al., 1994) rather than an absolute defective beta cell function per se. It may be speculated that insulin resistance and/or its concomitant hyperinsulinaemia could represent a compensatory "survival" mechanism in a undernourished early life environment redirecting scanty energy supplies from muscle to vital tissues such as the brain and/or - during periods with somewhat better supplies - to the more energy conserving adipose tissue. This idea is analogous to the "thrifty genotype hypothesis" proposed by Neel in 1962 (Neel, 1962), and the fetal origins hypothesis is therefore also known as "the thrifty phenotype hypothesis".

\section{Evidence from Twin Studies}

The association between low birth weight and the risk of Type 2 diabetes in some studies could theoretically be explained by a genetically determined reduced fetal growth rate. Thus, a reduced enhancement of growth in utero could be due to a putative genetically determined reduced insulin secretion - or action - in individuals predisposed to Type 2 diabetes. In other words, the genotype responsible for Type 2 diabetes may itself cause a retarded fetal growth in utero. This hypothetical scenario was illustrated by the findings that mutations for insulin receptor substrate-1 (IRS-1) may both cause low birth weight (Tanemoto et al., 1994), insulin resistance (Clausen et al., 1995) and increased risk of developing Type 2 diabetes in adult age (Almind et al., 1993).

Correction for factors influencing birth weight (i.e. gestational age, maternal height, birth order, sex and maternal nutrition status) in previous studies was either not performed or was associated with various degrees of uncertainty. Studying birth weights in twins discordant for Type II diabetes allows perfect matching for these factors thus any intrapair differences in birth weight are a measure of individual fetoplacental influences. Importantly, studying $\mathrm{MZ}$ twins in addition allows elimination of a putative influence of the genotype per se on fetal growth. Accordingly, we examined the impact of low birth weight on the development of Type II diabetes among MZ and DZ twins discordant for Type II diabetes. We found lower birth weights in MZ Type 2 diabetic twins compared with their genetically identical non-diabetic co-twins supporting the fetal origins hypothesis. In particular, the unique design eliminates the theoretical possibility that the association between low birth weight and risk of Type 2 diabetes could be explained solely by a coincidence between a/the "Type 2 diabetes susceptibility genotype" and impaired intrauterine growth per se (Poulsen et al., 1997; Figure 1).

McCance et al. (1994) proposed that a "Type 2 diabetes susceptibility genotype" possibly involving insulin resistance might favour survival in low birth weight infants. The point was also taken that the previous studies of the association between low birth weight and Type 2 diabetes did not take into account the higher perinatal mortality associated with low birth weight. Therefore, it was proposed that the association between low birth weight and Type 2 diabetes was perhaps not due to intrauterine nutritional factors, but rather due to the putative selective survival of low birth weight infants possessing a "thrifty" Type 2 diabetes susceptibility genotype (McCance et al., 1994). The finding of lower birth weights in both $\mathrm{MZ}$ and DZ twins developing Type 2 diabetes after an age of 40 years compared with their genetically identical and non-identical co-twins who did not develop Type 2 diabetes (Poulsen et al., 1997; Figure 1) does not support the "surviving small baby genotype" theory. In particular, our study design using individual non-diabetic cotwins of the Type 2 diabetes twins as "controls" cannot be criticised for not taking the higher perinatal mortality associated with low birth weight into account.

Based on the notion of differences in the intrauterine environment we compared the glucose and insulin profiles after oral glucose ingestion between elderly (mean age 66 years) MZ and DZ twins (Poulsen et al., 1999). We found that $\mathrm{MZ}$ compared with $\mathrm{DZ}$ twin status per se is associated with elevated $30 \mathrm{~min}$ - but not $120 \mathrm{~min}$ — post oral glucose plasma glucose and insulin concentrations in these 


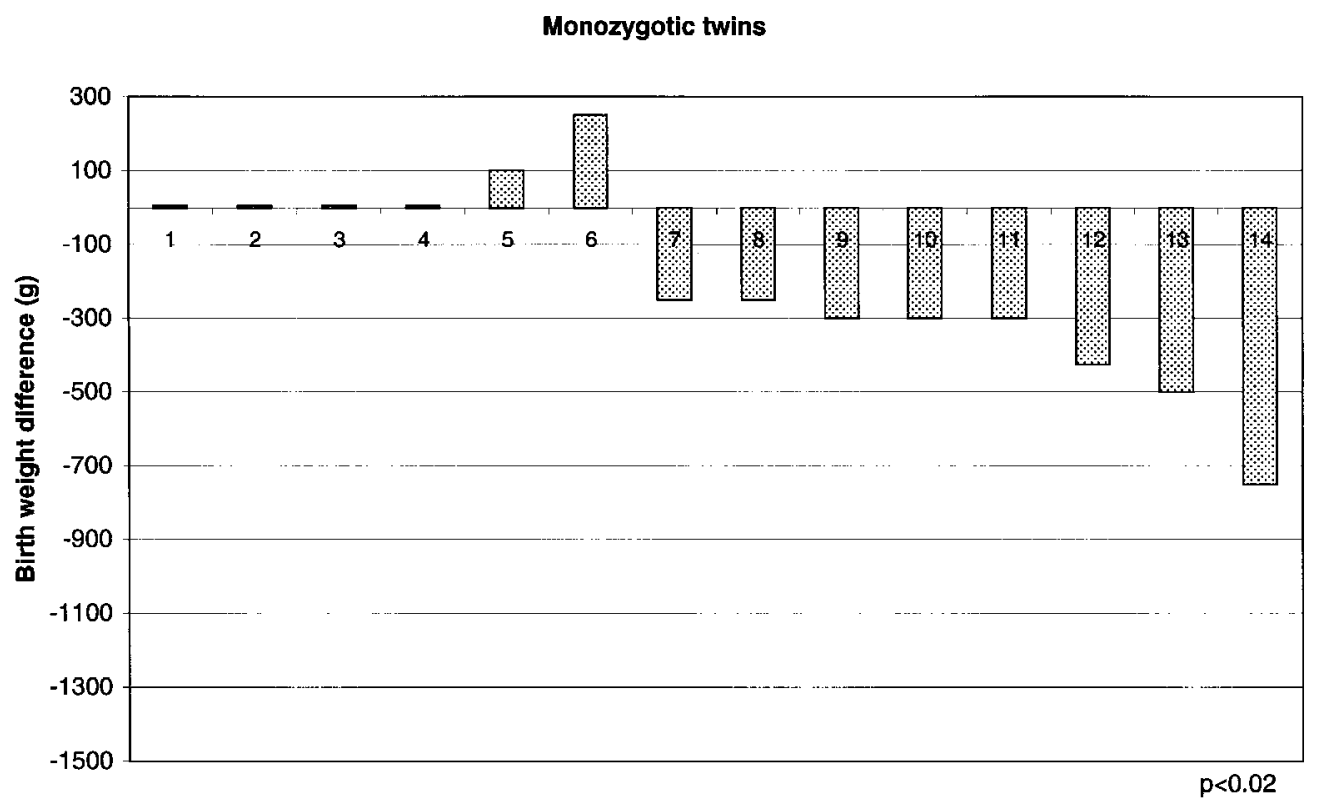

Dizygotic twins

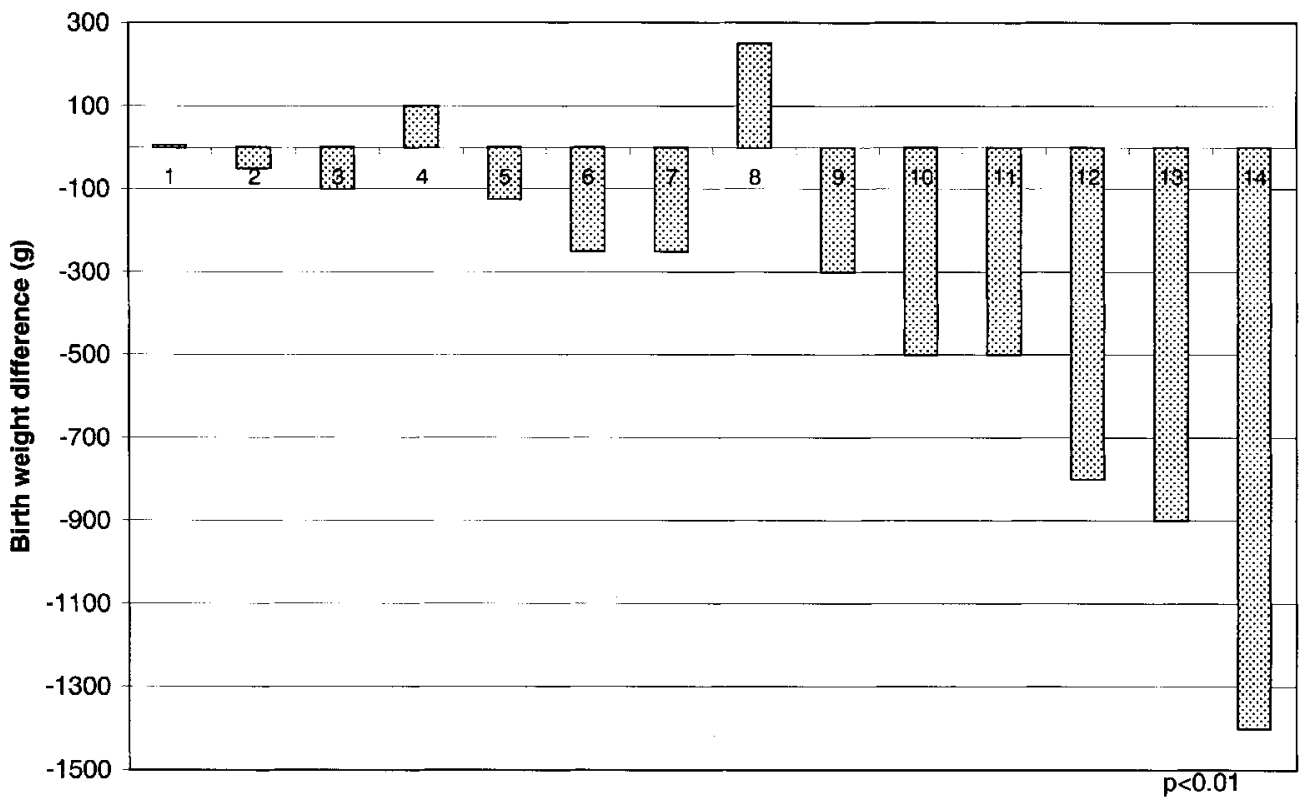

Figure 1.

Intrapair birth weight differences in MZ and DZ twin pairs discordant for Type 2 diabetes (i.e. birth weight of the diabetic twin minus birth weight of the individual non-diabetic co-twin). A negative value denotes a lower birth weight in the Type 2 diabetic twin compared with the corresponding non-diabetic co-twin within a given couple. Birth weight differences were "ranked" according to the absolute magnitude of differences. Zero values indicate similar birth weights in the diabetic and non-diabetic twins (7).

elderly twins (Poulsen et al., 1999). The differences between $\mathrm{MZ}$ and DZ twins were persistent even after exclusion of glucose intolerant twins and glucose tolerant twins with first degree diabetic relatives (Table 1), and the elevated plasma glucose and insulin concentrations found in this study cannot solely be explained by a theoretically larger prevalence of diabetes related genes among $\mathrm{MZ}$ compared to $\mathrm{DZ}$ twins. Excluding a genetic cause of the observed differences between the two groups, and assuming a comparable postnatal environment for $\mathrm{MZ}$ and $\mathrm{DZ}$ twins, the documented differences are most likely to be attributed to prenatal environmental factors. The finding of an elevated incremental insulin area under the curve in the $\mathrm{MZ}$ compared with $\mathrm{DZ}$ twins support the idea that the intrauterine environment influences disease status in man through the induction of insulin resistance. This may be true not only for Type 2 dia- 


\section{Table 1}

Clinical Characteristics and OGTT Glucose and Insulin Levels Among Monozygotic ( $n=108)$ and Dizygotic $(n=134)$

Twins Concordant for Normal Glucose Tolerance and Without First Degree Diabetic Relatives. Data are Presented as Mean (SD)

\begin{tabular}{|c|c|c|c|c|c|}
\hline \multirow[b]{2}{*}{$\mathrm{n}$ (male/female) } & \multicolumn{2}{|c|}{ Monozygotic } & Dizygotic & Difference of mean $(95 \% \mathrm{CI})$ & \multirow[t]{2}{*}{$P$ value } \\
\hline & 108 & $(54 / 54)$ & $134 \quad(66 / 68)$ & & \\
\hline Age (yrs) & 65.6 & $(5.0)$ & 65.0 & $0.6 \quad(-0.7-1.9)$ & NS \\
\hline Height (cm) & 168.1 & (9.5) & $167.4 \quad(8.6)$ & $0.7 \quad(-1.6-3.0)$ & NS \\
\hline Weight (kg) & 71.3 & (13.5) & $70.3(12.3)$ & $1.1 \quad(-2.2-4.3)$ & NS \\
\hline BMI (kg/m2) & 25.2 & 4.1) & $25.0 \quad(3.4)$ & $0.2 \quad(-0.7-1.2)$ & NS \\
\hline W/H ratio & 0.86 & $(0.08)$ & $0.85(0.09)$ & $0.01 \quad(-0.007-0.036)$ & NS \\
\hline \multicolumn{6}{|l|}{ OGTT plasma glucose (mmol/l) } \\
\hline $0 \mathrm{~min}$ & 5.6 & $(0.5)$ & $5.6 \quad(0.5)$ & $0.02(-0.11-0.14)$ & NS \\
\hline $30 \mathrm{~min}$ & 9.0 & (1.5) & $8.5 \quad(1.3)$ & $0.47 \quad(0.11-0.83)$ & $<0.02$ \\
\hline $120 \mathrm{~min}$ & 5.8 & (1.1) & $5.8 \quad(1.0)$ & $-0.03(-0.30-0.24)$ & NS \\
\hline AUC-glucose (min $x \mathrm{mmol} / \mathrm{l})$ & 214.4 & (88.3) & $189.8(78.4)$ & $24.6 \quad(3.45-45.7)$ & $<0.05$ \\
\hline \multicolumn{6}{|l|}{ Ln OGTT plasma insulin (pmol/l) } \\
\hline $0 \min$ & 3.53 & $(0.51)$ & $3.49(0.47)$ & $0.05(-0.08-0.17)$ & NS \\
\hline $30 \mathrm{~min}$ & 5.60 & $(0.67)$ & $5.37(0.57)$ & $0.23 \quad(0.07-0.39)$ & $<0.01$ \\
\hline $120 \mathrm{~min}$ & 5.03 & $(0.64)$ & $5.12(0.72)$ & $-0.08 \quad(-0.26-0.09)$ & NS \\
\hline AUC-insulin (min x pmol/l) & 9.92 & $(0.60)$ & $9.79(0.57)$ & $0.13(-0.02-0.28)$ & 0.08 \\
\hline
\end{tabular}

betes, but perhaps also for other components of the insulin resistance syndrome including essential hypertension and coronary heart disease. Unpublished data from the same study actually demonstrate significantly higher levels of total cholesterol and triglycerides, and a tendency to higher systolic blood pressure, among elderly $\mathrm{MZ}$ compared to $\mathrm{DZ}$ twins indicating an influence of zygosity on the lipid profile and possibly systolic blood pressure (manuscript submitted).

In support of our findings, Lehtovirta et al. (2000) reported elevated second phase insulin secretion after intravenous glucose ingestion in elderly $\mathrm{MZ}$ compared with $\mathrm{DZ}$ twins (mean age 62 years. However, in contrast to our data, a very recent study of twins born in Birmingham between 1950-1954 reported similar plasma glucose and insulin concentrations during oral glucose ingestion in $\mathrm{MZ}$ compared with DZ twins (Baird et al., 2001). The explanation for the different results compared with our data (Poulsen et al., 1999) may be the age of the twins in the two studies, and our reason to believe this is the following: Most previous studies addressing the impact of low birth weight or an adverse intrauterine environment on glucose and insulin metabolism in man were based upon indirect measures of insulin secretion and action. Accordingly, we have elaborated on our previous findings by studying in vivo insulin action in young and elderly twins using the gold standard euglycaemic hyperinsulinaemic clamp technique. Data from this recently finished study clearly demonstrate insulin resistance as reflected by a reduced insulin stimulated glucose uptake among elderly (mean age 62 years) MZ compared to DZ twins independent of the anthropometric measures usually associated with insulin action (i.e. lean body mass, body mass index and birth weight; Poulsen et al., 2000). Surprisingly, we found a slightly higher insulin stimulated glucose disposal among young (mean age 28 years) $\mathrm{MZ}$ compared with DZ twins. The significance of this finding is presently uncertain, but is supported by findings in animal models demonstrating higher insulin sensitivity among the very young (3 months) male offspring of protein-malnourished rats (Ozanne et al., 1996). Nevertheless, it is clear that this documented age dependence of the impact of zygosity status on insulin action and glucose metabolism in twins explains why Baird et al. (2001) were unable to find any differences in glucose and insulin concentrations among $\mathrm{MZ}$ compared with DZ twins with a mean age of 44 years and a total age span of only 4 years.

\section{Classical Twin Methodology}

The classical twin model (i.e. concordances and heritabilty indices) is used in the assessment of the relative contribution of genetic and environmental aetiological factors, respectively, to a given phenotype. This is based on the fact that $\mathrm{MZ}$ twins are genetically identical, whereas $\mathrm{DZ}$ twins only have $50 \%$ of their genes in common, like ordinary siblings. A greater similarity between MZ twin pairs has been interpreted as evidence of genetic aetiological factors. The classical twin model is based upon the key assumption that both prenatal and postnatal environmental covariance is the same for $\mathrm{MZ}$ and $\mathrm{DZ}$ twin pairs.

It was postulated already several years ago that the higher concordance rate of Type 2 diabetes in $\mathrm{MZ}$ compared with DZ twins could be due to their special intrauterine environment and undernutrition rather than genetics per se (Phillips et al., 1993; Phillips 1993). On the other hand, $\mathrm{MZ}$ monochorionic twin pairs may in some cases exhibit higher intrauterine growth discordance compared with DZ 
dichorionic twin pairs (Naeye, 1964; Pridjian et al., 1991). Accordingly, McDonald (1993) argued that any potential impact of low birth weight and intrauterine malnutrition for a given disease would result in lower concordance rates in MZ compared with DZ twins, and that this therefore would tend to mask a putative genetic component.

Our recent findings of differences in the metabolic profiles after oral glucose ingestion in $\mathrm{MZ}$ compared with $\mathrm{DZ}$ twins may to some extent question the validity of the classic twin approach in diabetes research assuming equal environmental influences in MZ and DZ twins (Poulsen et al., 1999). Nevertheless, zygosity status did not significantly influence the definition of diabetes per se based on either fasting or $120 \mathrm{~min}$ post oral glucose plasma glucose concentrations (Poulsen et al., 1999). This provides some indirect validation of the diabetes concordance rates as true estimates of genetic versus non-genetic factors in the aetiology of diabetes (Poulsen et al., 1999). In addition, one study reported normal longevity in $\mathrm{MZ}$ and $\mathrm{DZ}$ twin pairs (Christensen et al., 1995), indicating that low birth weight due to twin status did not represent a risk factor of excess mortality as a result of diabetes, hypertension or cardiovascular disease. Nevertheless, the study was performed in a selected subgroup of twins surviving the age of six years and did not include any specific data on the causes of death. As even high birth weight may be associated with excess mortality from common types of cancer (Michels et al., 1996; Tibblin et al., 1995), it can not be excluded that twins may have an altered disease pattern with a potentially lower prevalence of some cancer types together with higher prevalence of diabetes, hypertension and coronary heart disease. A major challenge in the near future will therefore be to expand on our knowledge of differences between $\mathrm{MZ}$ and $\mathrm{DZ}$ twins according especially to parameters related with diabetes, insulin resistance and related diseases. Studies addressing the roles of genes versus environment on those parameters using the classical twin model with appropriate corrections for the role of the intrauterine environment as assessed by birth weight determinations might be particular important in the continuous evaluation of any impact that the intrauterine environment may have in twins and results from twin studies. Thus, it is the present authors' opinion that much more documentation is required before abandoning the twin model as a tool to differentiate between the relative impact of genes versus environment.

\section{Conclusion}

Different lines of twin studies have provided important insights into a complicated interplay between genetic versus both pre- and post-natal environmental factors involved in the aetiology and pathophysiology of Type 2 diabetes. Although our present knowledge is far too insufficient to discard the results from "classical" twin studies concerning the relative role of genes versus environment for the development of diabetes and its metabolic defects, it is nevertheless clear that the "classical" twin model is challenged by the thrifty phenotype hypothesis and its implications of an adverse intrauterine environment for the development of several diseases in humans, including diabetes. Twins with their special intrauterine conditions may represent a help- ful tool in the continuous search for the mechanisms and the extent to which the early environment may play a role for the development of diabetes and its related states of disease including coronary heart disease in man.

\section{References}

Almind, K., Bjorbaek, C., Vestergaard, H., Hansen, T., Echwald, S., \& Pedersen, O. (1993). Aminoacid polymorphisms of insulin receptor substrate- 1 in non-insulin-dependent diabetes mellitus. Lancet, 342, 828-832.

Baird, J., Osmond, C., MacGregor, A., Snieder, H., Hales, C. N., \& Phillips, D. I. W. (2001). Testing the fetal origins hypothesis in twins: The Birmingham twin study. Diabetologia, 44, 33-39.

Bjōro, K., Jr., \& Bjōro, K. (1985). Disturbed intrauterine growth in twins: Etiological aspects. Acta Geneticae Medicae et Gemellologiae, 34, 73-79.

Christensen, K., Vaupel, J. W., Holm, N. V., \& Yashin, A. I. (1995). Mortality among twins after age 6: Fetal origins hypothesis versus twin method. British Medical Journal, 310, 432-436.

Clausen, J. O., Hansen, T., Bjorbaek, C., et al., (1995), Insulin resistance: Interactions between obesity and a common variant of insulin receptor substrate-1. Lancet, 346, 397-402.

Hales, C. N., Barker, D. J. P., Clark, P. M. S., Cox, L. J., Fall, C., Osmond, C., \& Winter, P. D. (1991). Fetal and infant growth and impaired glucose tolerance at age 64. British Medical Journal, 303, 1019-1022.

Hales, C. N. \& Barker, D. J. (1992). Type 2 (non-insulin-dependent) diabetes mellitus: The thrifty phenotype hypothesis. Diabetologia, 35, 595-601.

Hofman, P. L., Cutfield, W. S., Robinson, E. M., Bergman, R. N., Menon, R. K., Sperling, M. A., \& Gluckman, P D. (1997). Insulin resistance in short children with intrauterine growth retardation. The Journal of Clinical Endocrinology and Metabolism, 82, 402-406.

Leger, J., Levy-Marchal, C., Bloch, C., Pinet, A., Chevenne, D., Porquet, D., Collin, D., \& Czernichow, P. (1997). Reduced final height and indications for insulin resistance in 20 year olds born small for gestational age: Regional cohort study. British Medical Journal, 315, 341-347.

Lehtovirta, M., Kaprio, J., Forsblom, C., Eriksson, J., Tuomilehto, J., \& Groop, L. (2000). Insulin sensivity and insulin secretion in monozygotic and dizygotic twins. Diabetologia, 43, 285-293.

McCance, D. R., Pettitt, D. J., Hanson, R. L., Jacobsson, L. T. H., Knowler, W. C., \& Bennett, P. H. (1994). Birth weight and non-insulin dependent diabetes: Thrifty genotype, thrifty phenotype, or surviving small baby genotype? British Medical Journal, 308, 942-945.

McDonald, A. M. (1993). Twin studies in medical research. Lancet, 341, 1419 (letter).

Michels, K. B., Trichopoulos, D., Robins, J. M., Rosner, B. A., Manson, J. E., Hunter, D. J., Colditz, G. A., Hankinson, S. E., Speizer, F. E. \& Willett, W. C. (1996). Birthweight as a risk factor for breast cancer. Lancet, 348, 1542-1546.

Naeye, R. L. (1964). The fetal and neonatal development of twins. Pediatrics, 33, 546-549. 
Naeye, R. L., Benirschke, K., Hagstrom, J. W. C., \& Marcus, C. C. (1966). Intrauterine growth of twins as estimated from liveborn birth weight data. Pediatrics, 37, 409-416.

Neel, V. (1962). Diabetes mellitus: A "thrifty" genotype rendered detrimental by "progress"? American Journal of Human Genetics, 14, 353-362.

Ozanne, S. E., Wang, C. L., Coleman, N., \& Smith, G. D. (1996). Altered muscle insulin sensivity in the male offspring of protein-malnourished rats. American Journal of Physiology, 271 (Endocrinology and Metabolism 34), E1128-E1134.

Phillips, D. I., Hales, C. N., \& Barker, D. J. (1993). Can twin studies assess the genetic component in type 2 (non-insulindependent) diabetes mellitus? [letter; comment]. Diabetologia, $36,471-472$.

Phillips, D. I. W. (1993). Twin studies in medical research: Can they tell us whether diseases are genetically determined ? Lancet, 341, 1008-1009.

Phillips, D. I. W., Barker, D. J. P., Hales, C. N., Hirst, S. \& Osmond, C. (1994). Thinness at birth and insulin resistance in adult life. Diabetologia, 37, 150-154.

Poulsen, P.,Vaag, A., Kyvik, K. O., Møller-Jensen, D., \& Beck-Nielsen, H. (1997). Low birth weight is associated with non-insulin-dependent diabetes mellitus in discordant $\mathrm{MZ}$ and DZ twin pairs. Diabetologia, 40, 439-446.

Poulsen, P., Kyvik, K. O., Vaag, A., \& Beck-Nielsen, H. (1999). Heritability of Type II (non-insulin-dependent) diabetes mellitus and abnormal glucose tolerance - a population-based twin study. Diabetologia, 42, 139-145.
Poulsen, P., Vaag, A., \& Beck-Nielsen, H. (1999). Does zygosity influence the metabolic profile in twins? A population based cross sectional study. British Medical Journal, 319, 151-154.

Poulsen, P., Levin, K., Vaag, A., \& Beck-Nielsen, H. (2000). The impact of zygosity and age on in vivo insulin action. Diabetes Research and Clinical Practice, 50(1), S101.

Pridjian, G., Nugent, C. E., \& Barr, M., Jr. (1991). Twin gestation: Influence of placentation on fetal growth. American Journal of Obstetrics and Gynecology, 165, 1394-1401.

Ramas-Arroyo, M. A., Ulbright, T. M., Yu, P. L., \& Christian, J. C. (1988). Twin study: Relationship between birth weight, zygosity, placentation and pathologic placental changes. Acta Geneticae Medicae et Gemellologiae, 37, 229-38.

Sadler, T. W. (1995). Fetal membranes and placenta. In T. W. Sadler (Ed.), Langman's medical embryology (pp. 101-121). Sydney: Williams \& Wilkins.

Tamemoto, H., Kadowaki, T., Tobe, K., Yagi, T., Sakura, H., Hayakawa, T., Terauchi, Y., Ueki, K., Kaburagi, Y., Satoh, S., Sekihara, H., Yoshioka, S., Horikoshi, H., Furuta, Y., Ikawa, Y., Kasuga, M., Yazaki, Y., \& Aizawa, S. (1994). Insulin resistance and growth retardation in mice lacking insulin receptor substrate-1. Nature, 372, 182-186.

Tibblin, G., Eriksson, M., Cnattingius, S., \& Ekblom, E. (1995). High birth weight as a predictor of prostate cancer risk. Epidemiology, 6, 423-424.

Valdez, R., Athens, M. A., Thompson, G. H., Bradshaw, B. S., \& Stern, M. P. (1994). Birthweight and adult health outcomes in a biethnic population in the USA. Diabetologia, 37, 624-631. 